\title{
L. Levantis, Venise, un spectacle d'eau et de pierres. Architecture et paysage dans les récits de voyageurs français 1756-1850
}

\section{Michel Arrous}

\section{(2) OpenEdition}

\section{Journals}

\section{Édition électronique}

URL : http://journals.openedition.org/studifrancesi/9986

DOI : 10.4000/studifrancesi.9986

ISSN : 2427-5856

Éditeur

Rosenberg \& Sellier

\section{Édition imprimée}

Date de publication : 1 août 2017

Pagination : 369-370

ISSN : 0039-2944

\section{Référence électronique}

Michel Arrous, «L. Levantis, Venise, un spectacle d'eau et de pierres. Architecture et paysage dans les récits de voyageurs français 1756-1850 », Studi Francesi [En ligne], 182 (LXI | II) | 2017, mis en ligne le 01 août 2017, consulté le 07 janvier 2021. URL : http://journals.openedition.org/studifrancesi/9986 ; DOI : https://doi.org/10.4000/studifrancesi.9986

Ce document a été généré automatiquement le 7 janvier 2021.

\section{cc) $(9)$}

Studi Francesi è distribuita con Licenza Creative Commons Attribuzione - Non commerciale - Non opere derivate 4.0 Internazionale. 


\title{
L. Levantis, Venise, un spectacle d'eau et de pierres. Architecture et paysage dans les récits de voyageurs français 1756-1850
}

\author{
Michel Arrous
}

\section{RÉFÉRENCE}

LAETITIA LEVANTIS, Venise, un spectacle d'eau et de pierres. Architecture et paysage dans les récits de voyageurs français 1756-1850, Grenoble, ELLUG, 2016, 291 pp.

$\mathrm{Au}$ carrefour de l'histoire culturelle et de l'histoire de l'art, la thèse remaniée de Laetitia Levantis mérite sa place dans la collection «Italie plurielle» car, du Voyage pittoresque d'Italie de Cochin (1756) à l'Italia de Gautier (1852), elle offre sur les pratiques et les sensibilités des voyageurs français face à l'architecture et au paysage vénitiens, un éclairage nouveau. À cela s'ajoutent des aspects parfois méconnus, voire insoupçonnés, ce qui mérite d'être signalé car les représentations littéraires qui ont façonné le mythe de Venise au xIx siècle ont fait l'objet de nombreux travaux consacrés à Chateaubriand, Stendhal, Sand, Gautier, etc., qui ont été exploités (on regrette que pour Stendhal n'ait pas été menée une lecture attentive du journal de juin 1815 et de sa transposition dans Rome, Naples et Florence en 1817). Dans les relations retenues, ce n'est pas tant l'écriture elle-même qui est privilégiée que les mutations dans l'attitude des visiteurs face à l'urbanisme et à l'environnement de la cité, leurs réactions au langage stylistique de l'architecture vénitienne, leur perception du paysage lagunaire et leur expérience de l'eau menaçante ou bienfaisante. S'il est vrai que les romantiques ont beaucoup pratiqué la Sérénissime qui a nourri leur imaginaire - Stendhal et Gautier en ont même parlé avant de l'avoir vue! -, l'expression «génération romantique» paraît inappropriée: si Jacques Cambry (1749-1807) peut être 
considéré comme un précurseur des romantiques, on se demande à quel titre y figurent le baron d'Haussez (1778-1854), qui fit partie du ministère Polignac, l'érudit A.-C. Pasquin, dit Valéry, et d'autres qui furent, comme on dit, des «romantiques sans convulsions» ou dont la «manière de sentir» (Baudelaire) n'eut rien de romantique.

2 L'intérêt de cette recherche réside d'abord dans l'analyse de la perception de la complexité d'un corps urbain qui a expulsé la nature (c'est sous l'administration napoléonienne que fut créé le premier jardin public). Si le foisonnement architectural déroute les voyageurs des Lumières plutôt attirés par Palladio (leur désintérêt pour les fresques des Tiepolo n'est pas relevé), il séduit leurs successeurs sensibles à l'exotisme du décor. Tous mesurent les ravages de l'eau sur la «Palmyre de la mer» et ne manquent pas de signaler la décrépitude d'une ville qui a perdu sa puissance et ses fêtes avec le traité de 1797. S'impose, et durablement, l'image d'une cité au crépuscule, à vrai dire une belle mourante. Pour L. Levantis, «ce constat mérite d'être quelque peu nuancé» (p. 119) car la ville continue à vivre, se modernise - construction du chemin de fer en 1846 - et connaît dès les années 1830 des changements que peu de visiteurs étrangers ont notés, sans doute parce qu'ils étaient plus marqués par la nostalgie d'un régime aristocratique idéal («Pour moi, je dirai toujours: Vive le despotisme de l'ancien gouvernement de Venise!», s'écrie Stendhal qui voit dans la Venise d'avant Campoformio la «ville la plus heureuse du monde», de même Arsène Houssaye évoquant l'allegria perdue) que par les insatisfactions de la génération romantique. Il leur semble - tel Chateaubriand - que la ville échappe à la modernité, qu'elle est «étrangère à l'esprit de l'Europe du début du xix ${ }^{e}$ siècle» (p. 123). Domine alors le thème de la cité défunte, quoique sous la passivité apparente et l'indolence prétendue de ses habitants, sans omettre le discours prophétique sur le lent engloutissement de la cité, apparaissent les premiers signes d'un essor économique. Après 1840 on voit poindre quelques efforts de restauration. Les chapitres IV et V, parmi les plus originaux, permettent d'apprécier les changements, certains dès l'époque napoléonienne, avec l'émergence d'une vision positive du Moyen Âge chez les architectes Rohault de Fleury ou J.-L. Durand, un disciple de Séroux d'Agincourt, ou comme en témoigne en 1837-1838 le jeune Viollet-le-Duc dans les pages vénitiennes de son journal. L. Levantis fait alors de fort pertinentes remarques (pp. 157-166) sur l'appréhension du gothique vénitien auquel, jusqu'à Chateaubriand, on assigna une origine orientale. Sont opportunément mentionnées les propositions de Quatremère de Quincy et d'Adalbert de Beaumont sur le caractère «arabe» de cette architecture, et les observations de Viollet-le-Duc qui la juge plus gothique que mauresque.

3 L'apport décisif de cette recherche réside dans les informations et les analyses qui en découlent, sur l'univers insulaire dont les voyageurs avaient si souvent relevé les caractéristiques qu'elles s'étaient transformées en de véritables stéréotypes du voyage à Venise: on citera la crainte de l'eau, la puanteur des canaux (Veuillot n'a pas écrit Le parfum de Venise!), les risques sanitaires (la malaria, plus tard le choléra dans la nouvelle de Thomas Mann, etc.). Non sans surprise, on apprend qu'au début du xix siècle le discours des médecins vénitiens vante Venise (pp. 176-177) au prétexte que la lagune échapperait au mauvais air des plages italiennes. En 1816 déjà, un médecin aériste avait recommandé à Stendhal d'aller à Padoue et à Venise pour changer d'air. Simultanément la fascination de la lagune s'empare des esprits et dans l'imaginaire des voyageurs se construit un univers autre, la Venise étrange qui stimule la contemplation et la rêverie («les romantiques font du rivage un lieu privilégié de la découverte de soi», 
p. 199). De Stendhal aux Goncourt donc, mais l'attirance pour le monde lagunaire ne s'arrête pas aux écrivains; elle est aussi partagée par les scientifiques conscients de la fragilité du site qui s'interrogent sur la survie de la «Reine des eaux». Dans la première moitié du XIX siècle, à la «Venise miasmatique et décadente» (p. 219) s'oppose le discours des médecins et scientifiques vénitiens et français sur le "grand pouvoir curatif du microclimat marin de la ville dans le traitement de diverses affections dont la tuberculose» (pp. 220-229). Sans pour autant les cautionner ou les réfuter, L. Levantis note que leurs hypothèses extraordinaires témoignent d'un intérêt nouveau pour l'environnement vénitien. Il y eut heureusement des projets plus raisonnables, ceux des ingénieurs hydrauliciens Grimaud de Caux et Degousée pour alimenter une ville entourée d'eau mais privée d'eau potable. Le chapitre IX et dernier, «La médication par les eaux et le climat: Venise, station médicale et balnéaire au XIX ${ }^{\mathrm{e}}$ siècle» (pp. 235-259), est tout aussi nouveau et paradoxal puisque cette ville, où n'étaient guère respectés les principes sanitaires, va offrir d'inattendues ressources thérapeutiques et devenir une des grandes stations thermales européennes. À partir de 1830, la littérature médicale promeut les propriétés bénéfiques du climat et des eaux lagunaires: le Dr Brera affirme en 1838 que l'air des canaux «anime l'esprit et rend l'âme hilare»; son confrère Rima entend si bien la balnéothérapie qu'il fait fortune avec ses bains flottants devant la pointe de la Douane (voir le cahier d'illustrations, fig. 16 à 21), où se rencontreront les protagonistes de Senso, la nouvelle de C. Boito (1883) qui inspira Visconti (1954). Si la balnéation de loisir n'était pas une activité nouvelle à Venise (Byron l'avait pratiquée, de même Stendhal qui trouva en 1815 son bain dans le canal de la Giudecca «fort agréable et probablement fort sain»), la balnéothérapie transforme le parc hôtelier en investissant ou en réaménageant certains palais, par exemple le palazzo Grassi en 1842, célèbre pour ses bains dans une eau prélevée «dans le site le plus pur du Grand Canal» (selon un guide pour étrangers), réservée à un tourisme d'élite. La Venise des voyageurs du Grand Tour, remise à la mode grâce à ceux de la génération romantique, était devenue un pôle thermal et mondain. Le miracle d'art et d'histoire a donc connu dans les années 1850 l'âge d'or des stations balnéaires, avant de subir l'assaut des troupes débarquant de paquebots géants dont les remous rongent les grèves. La mort de Venise? 